\title{
Recovery of anaerobic bacteria from small inocula: a model for blood culture studies
}

\author{
J. G. COLLEE, B. I. DUERDEN, ${ }^{1}$ AND R. BROWN
}

\begin{abstract}
From the Bacteriology Department, University of Edinburgh Medical School, Teviot Place, Edinburgh EH8 $9 A G$
\end{abstract}

SUMMARY The recovery of anaerobic, facultative anaerobic, and aerobic pathogens from very small inocula was studied under conditions that could be related to routine blood culture procedures. Results with Brain Heart Infusion broth were unsatisfactory. Freshly prepared Brewer thioglycollate medium gave apparently good results, but there are disadvantages when this medium is used for blood culture. Results with Difco Thiol broth were disappointing. A modification of Robertson's cooked-meat broth supplemented with Brain Heart Infusion gave good recovery and sustained viability with a wide range of test organisms including exacting strains. The findings raise points of practical importance.

Although the recovery of certain blood-borne pathogens demands special laboratory procedures, there is a continuing requirement for a general blood culture procedure for use as a routine that might effectively detect a wide range of likely pathogens. This obliges laboratory workers to review their blood culture procedures periodically, to be aware of new technical developments (Brooks and Sodeman, 1974; Smith and Little, 1974; Thiemke and Wicher, 1975; Wood, 1976), and to consider the media used (Washington, 1971; Chow and Guze, 1974; Forgan-Smith and Darrell, 1974; Gantz et al., 1974; Shanson, 1974; Blazevic et al., 1975; Shanson and Barnicoat, 1975; Szawatowski, 1976). In view of developments in clinical anaerobic bacteriology, we studied the recovery of anaerobic pathogens from very small inocula under conditions that could be related to routine blood culture procedures. The study was then extended to the recovery of aerobic or facultative anaerobic pathogens associated with bacteraemic conditions in man.

\section{Material and methods}

\section{OR G ANISMS}

The following strains were used: Bacteroides fragilis ss. fragilis NCTC nos. 9343 and 9344; B. melaninogenicus ss. intermedius NCTC no. 9336; B. melanino-

\footnotetext{
${ }^{1}$ Present address: Department of Medical Microbiology, University of Sheffield Medical School, Beech Hill Road, Sheffield S10 2RX

Received for publication 17 January 1977
}

genicus ss. asaccharolyticus NCTC no. 9337; Fusobacterium polymorphum NCTC no. 10562; anaerobic coccus group I NCTC no. 9801 ; anaerobic coccus group III NCTC no. 9803; and laboratory stock strains of Staphylococcus aureus, Escherichia coli, Pseudomonas aeruginosa, Clostridium welchii, Streptococcus pneumoniae, Str. viridans, Haemophilus influenzae, and Neisseria meningitidis.

MEDIA

These were: (i) Brain Heart Infusion broth (Oxoid) prepared according to the manufacturer's instructions (BHI); (ii) Brain Heart Infusion broth (Oxoid) with $1 \mathrm{~g} /$ litre $(0 \cdot 1 \%)$ sodium thioglycollate (BHIThio); (iii) Brewer Thioglycollate Medium (Oxoid) containing dextrose $5 \mathrm{~g} / \mathrm{l}$ prepared according to the manufacturer's instructions (Brewer); (iv) Robertson's cooked-meat broth (Cruickshank et al., 1975) made in this department with nutrient broth (Oxoid no. 2) as the liquid phase of the medium (CMB); (v) a cooked-meat medium comprising fresh cookedmeat particles prepared as above with Brain Heart Infusion broth (Oxoid) as the liquid phase (BHI/ CMP); (vi) commercially prepared blood-culture bottles containing $50 \mathrm{ml}$ Bacto-Thiol broth with $\mathrm{CO}_{2}$ under vacuum were purchased from Difco Laboratories (Difco Thiol broth); (vii) blood agar plates made by adding $5 \%$ outdated human blood to Oxoid Columbia agar base; each $500 \mathrm{ml}$ of the human blood preparation contained $2 \mathrm{~g}$ disodium citrate and $1.7 \mathrm{~g}$ dextrose in $70 \mathrm{ml}$ water added to $430 \mathrm{ml}$ whole blood; (viii) plates of lysed blood agar supplemented with filter-sterilised menadione(Sigma, 
London) $1 \mu \mathrm{g} / \mathrm{ml}$ were used for subculture of $B$. melaninogenicus (see Duerden et al., 1976).

In the initial experiments $50-\mathrm{ml}$ medical flat bottles containing $17 \mathrm{ml}$ of BHI, BHI-Thio, Brewer medium, or CMB (1 cm-depth of cooked-meat particles with $17 \mathrm{ml}$ of nutrient broth) were used. This maintained the same surface:depth and media: bottle volume ratios as with the $150-\mathrm{ml}$ medical flat bottles containing $50 \mathrm{ml}$ of medium that are routinely used for blood culture in the Royal Infirmary, Edinburgh. The latter bottles were used in subsequent experiments. All bottles had perforated metal caps with rubber liners; the perforation was sealed with either a Viskap or autoclave tape.

Unless otherwise stated, bottles were autoclaved with the caps loose; they were tightened as soon as the bottles were cool enough to handle, and further cooling created a partial vacuum in the bottles ('normal' headspace). In the first series of experiments an atmosphere of $10 \%$ hydrogen, $10 \%$ carbon dioxide, and $80 \%$ nitrogen was introduced into one set of bottles of each medium (headspace ' $\mathrm{H}_{2}: \mathrm{CO}_{2}: \mathrm{N}_{2}$ ') as follows: a cylinder containing the gas mixture was connected through a reducing valve to the exhaust valve of the autoclave; the bottles were autoclaved with their caps loose; when the autoclave pressure had fallen to atmospheric pressure, the exhaust valve was opened and the gas mixture flowed into the autoclave as it cooled; after 15 minutes the autoclave was opened and the bottle caps were quickly tightened.

BLOOD FOR THE BLOOD CULTURE MODEL Defibrinated horse blood (Wellcome) was added to each bottle; $5 \mathrm{ml}$ was added to $50 \mathrm{ml}$ of medium in $150-\mathrm{ml}$ bottles and $1.5 \mathrm{ml}$ to $17 \mathrm{ml}$ of medium in $50-\mathrm{ml}$ bottles.

\section{INOCULUM}

Stationary phase cultures of test strains (48-hour cultures of $B$. melaninogenicus strains and 24-hour cultures of other species) in cooked-meat broth or a suitable nutrient broth were diluted in pre-steamed nutrient broth to provide an inoculum of approximately $10 \mathrm{cfu}$ per bottle. The dilutions were made on the basis of a total cell count with a $0.1 \mathrm{~mm}$ Thoma counting chamber (Hawksley, England) and phase-contrast microscopy (see Collee et al., 1972). A surface viable count was performed by a spreadplate method (see Watt et al., 1973) to determine the actual inoculum size. For the initial series of experiments with $50-\mathrm{ml}$ bottles the inoculum was prepared by serial dilution in pre-steamed nutrient broth with the final dilution in defibrinated horse blood so that $1.5 \mathrm{ml}$ was calculated to contain $10 \mathrm{cfu}$; this was injected from a syringe through the cap of the bottle.
In the subsequent studies with the 150 -ml bottles, horse blood $(5 \mathrm{ml})$ was injected into each bottle and then a $0.1 \mathrm{ml}$ inoculum of a suitable serial dilution in pre-steamed nutrient broth. The following procedure $(\mathrm{P})$ was adopted to check the variation in inoculum size between bottles: $0.1 \mathrm{ml}$ inocula of the final dilution, estimated to contain approximately $10 \mathrm{cfu}$, were injected alternately into the bottles of test media and on to fresh plates of blood agar or lysed blood agar (bottle-plate-bottle-plate) throughout the series of tests; colonies were counted on the blood agar plates after anaerobic incubation for 48 hours.

\section{INCUBATION}

All incubation was at $37^{\circ} \mathrm{C}$. The atmosphere inside the bottle depended upon the method of preparation until the bottles were opened for the first subculture; this admitted room air to the bottles. Unless otherwise stated, the bottles were thereafter simply incubated in a laboratory incubator. For 'anaerobic $+\mathrm{CO}_{2}$ ' incubation the bottles were vented by the insertion through the rubber seal of a sterile needle (25G $5 / 8$ in) plugged with sterile cotton wool and incubated in a BTL anaerobic jar. A standard anaerobic procedure based on that of Collee $e t$ al. (1972) was followed for these bottles and for all anaerobically incubated plates. The bottles were examined daily for haemolysis and turbidity.

\section{SUBCULTURES}

In general, the seeded bottles were subcultured on to fresh plates of blood agar or lysed blood agar by sampling $(c 0.03 \mathrm{ml})$ with a sterile wire loop after mixing the contents by gentle rotation (but not inversion). In some studies, e.g. when we compared the effects of different headspace gases, and when we compared recovery in bottles autoclaved with the caps either tight or loose, we did not subculture from the bottles until they had been incubated for 48 hours. In the other studies, Gram smears and subcultures were generally made after overnight incubation (18-20 h) and thereafter daily for up to seven days, with one subculture missed usually at day 5 or 6 . Subculture plates were examined after they had been incubated for 48 hours and again at four days. Aerobic plates were prepared with the test anaerobe series as a check for aerobic contaminants.

\section{Results}

COMPARISON OF MEDIA AND CONDITIONS In the first part of the investigation we used small bottles and studied the ability of BHI, BHI-Thio, Brewer medium, and CMB to support the growth of 
Table 1 Results of replicate studies with small inocula of two strains in four media with different headspace atmospheres

\begin{tabular}{|c|c|c|c|c|c|c|c|}
\hline \multirow{3}{*}{$\begin{array}{l}\text { Medium } \\
\text { BHI }\end{array}$} & \multirow{3}{*}{$\begin{array}{l}\text { Headspace atmosphere } \\
\text { Normal }\end{array}$} & \multicolumn{6}{|c|}{ Recovery (no. of bottles positive out of 3) with test strain } \\
\hline & & \multicolumn{4}{|c|}{ B. fragilis ss. fragilis } & \multicolumn{2}{|c|}{$\begin{array}{l}\text { B. melaninogenicus ss. } \\
\text { intermedius }\end{array}$} \\
\hline & & 2 & 0 & 2 & 1 & $\mathbf{0}$ & $\mathbf{0}$ \\
\hline & $\mathrm{H}_{2}: \mathrm{CO}_{2}: \mathrm{N}_{2}$ & 2 & 3 & - & 0 & 0 & $\mathbf{0}$ \\
\hline & Anaerobic $+\mathrm{CO}_{2}$ & - & - & 0 & 1 & 0 & $\mathbf{0}$ \\
\hline \multirow{3}{*}{ BHI + thioglycollate } & Normal & 1 & 3 & 1 & 3 & $\mathbf{0}$ & 0 \\
\hline & $\mathrm{H}_{2}: \mathrm{CO}_{2}: \mathrm{N}_{2}$ & 3 & 3 & - & 3 & 2 & $\mathbf{0}$ \\
\hline & Anaerobic $+\mathrm{CO}_{2}$ & - & $\overline{2}$ & 2 & 3 & 1 & $\mathbf{0}$ \\
\hline \multirow[t]{3}{*}{ Brewer } & Normal & 3 & 3 & 3 & 3 & 3 & 2 \\
\hline & $\mathrm{H}_{2}: \mathrm{CO}_{2}: \mathrm{N}_{2}$ & 3 & 3 & 一 & 3 & 3 & 3 \\
\hline & Anaerobic $+\mathrm{CO}_{2}$ & 一 & - & 1 & 3 & 3 & 3 \\
\hline \multirow[t]{3}{*}{ CMB } & Normal & - & 一 & 一 & 3 & - & 3 \\
\hline & $\mathrm{H}_{2}: \mathrm{CO}_{2}: \mathrm{N}_{2}$ & 一 & 一 & 一 & 3 & - & 3 \\
\hline & Anaerobic $+\mathrm{CO}_{2}$ & $\overline{\varepsilon n}$ & $\overline{7}$ & - & 3 & - & 3 \\
\hline \multicolumn{2}{|l|}{ Inoculum size $\dagger$} & 500 & $7 \cdot 4$ & 13 & 17 & 8 & $10 \cdot 5$ \\
\hline
\end{tabular}

*Each column shows results for one set of experiments, $-=$ not done for that set

†Mean no. of bacteria (cfu) inoculated per bottle

small inocula of $B$. fragilis ss. fragilis NCTC no. 9343 and $B$. melaninogenicus ss. intermedius NCTC no. 9336. Table 1 is a composite table summarising the results of a series of six experiments in which the variables were the four media, three different headspace atmospheres ('normal', ' $\mathrm{H}_{2}: \mathrm{CO}_{2}: \mathrm{N}_{2}$ ', and 'anaerobic $+\mathrm{CO}_{2}$ ') and the two test organisms. $\mathrm{A}$ set of three replicate bottles was seeded for each variable in each experiment. In general, there was no recovery of $B$. melaninogenicus ss. intermedius and there was unsatisfactory recovery of $B$. fragilis ss. fragilis in BHI medium. Recoveries were marginally improved but still unsatisfactory when the BHI medium was supplemented with thioglycollate (BIHI-Thio). Recoveries were much better with Brewer thioglycollate medium, but there was a clear disadvantage in the rapid loss of viability that we observed when cultures were held for more than a few days in this medium. For example, Brewer cultures yielding good growths of the test organism on subculture plates at days 2-4 often gave relatively scanty growths on days 4-6 and no growth on days 6-7. With the occasional exception of an exacting $B$. melaninogenicus strain, which sometimes showed diminished viability at seven days, cultures of the test organisms in cooked-meat media generally maintained their viability and gave good growths on subculture plates up to seven days. There was good recovery and maintained viability in our tests with cooked-meat broth; we already knew that this medium was favourable for the growth of a wide range of anaerobic and aerobic organisms as a result of our experience in this laboratory over many years.

In most cases a positive culture declared itself within 48 hours except with BHI broth, with which incubation was sometimes necessary for seven days before a positive recovery was obtained. As these studies indicated the superior value of cooked-meat particles compared with thioglycollate for the recovery and maintained viability of these test strains from small inocula, we sought to combine the reducing value of cooked-meat particles with the known nutritive value of BHI broth, particularly with a view to extending the study to a wider range of organisms.

The recoveries of two strains of $B$. fragilis ss. fragilis, NCTC nos. 9343 and 9344, and one strain of B. melaninogenicus ss. asaccharolyticus, NCTC no. 9337, were compared in full-size $(150-\mathrm{ml})$ bottles of $\mathrm{BHI}$ and $\mathrm{BHI} / \mathrm{CMP}$, incubated for up to seven days; BHI gave clearly unsatisfactory results (three successes and six failures) whereas BHI/CMP gave successful recoveries in all nine tests at three days.

\section{VARIATION IN INOCULUM SIZE}

At this stage we studied variation in inoculum size in detail and the procedure $P$ (see Methods) was instituted to check the possibility that some bottles might obtain no cells in the inoculum. Plates inoculated with reputedly minimal inocula alternately in series with bottles showed a range of counts as follows: with $B$. fragilis ss. fragilis NCTC no. 9344 , the estimated inoculum was $4.6 \mathrm{cfu}$ and the plate counts were $9,6,5,4,6,8,6,5,1,10,1,5$, $6,1,5,2,7,4$; mean $5 \cdot 05$; SD 2.62. With $B$. melaninogenicus ss. intermedius NCTC no. 9336, the estimated inoculum was $12 \cdot 3 \mathrm{cfu}$ and the plate counts were: $8,17,15,14,13,20,12,13,10,9,19,18,8,14,9,17$, $13,10,15,12$; mean $13 \cdot 35$, SD $4 \cdot 67$. One strain, $B$. melaninogenicus ss. asaccharolyticus NCTC no. 9337 , was sometimes unable to grow as colonies when the inoculum fell below a critical level of about $100 \mathrm{cfu}$ 
on a plate. In this case we sometimes had to rely upon dilutions estimated from total cell counts to achieve minimal inocula for fluid media.

\section{AUTOCLAVING WITH CAPS LOOSE OR TIGHT}

The reducing effect of cooked-meat particles, and the maintenance of this effect during subsequent storage of bottles, depends partly upon the driving off of dissolved oxygen during autoclaving and the subsequent exclusion of air from the bottle headspace after autoclaving. We therefore compared the recoveries of $B$. fragilis ss. fragilis NCTC no. 9344 and $B$. melaninogenicus ss. asaccharolyticus NCTC no. 9337 in BHI and BHI/CMP in parallel series: one autoclaved with the caps loose and thereafter immediately tightened while the bottles were still hot; the other autoclaved with the caps tight throughout. The results given in Table 2 were obtained. It is clear that it is essential to autoclave these bottles with the caps loose and to tighten them promptly after autoclaving. This is true even with BHI/CMP broth.

\section{BHI/CMP COMPARED WITH DIFCO THIOL BROTH}

At this point the value of Difco Thiol broth as a general purpose blood-culture medium was suggested by Szawatowski (1976). Accordingly, we compared Difco Thiol broth with our BHI/CMP medium and we used an extended range of five anaerobes for this study. The results are given in Table 3. The superiority of the BHI/CMP medium is clear; there was only one failure in 25 tests. Contamination was a major problem with the Difco Thiol bottle. We are in no doubt that we introduced the contaminants, most frequently at the first subculture stage when the aseptic manipulation of the rubber stopper proved difficult, but the main point is that one of the test strains was not recovered in the Difco Thiol series, and recovery of another test strain was poor. The experiment with Fusobacterium polymorphum was repeated with special aseptic precautions that

Table 2 Effect on subsequent recoveries if media are autoclaved in bottles with caps loose or tight

\begin{tabular}{|c|c|c|c|}
\hline \multirow[t]{2}{*}{ Medium } & \multirow{2}{*}{$\begin{array}{l}\text { Bottle caps } \\
\text { tight or } \\
\text { loose in } \\
\text { autoclave }\end{array}$} & \multicolumn{2}{|c|}{$\begin{array}{l}\text { Recovery (no. of bottles positive out of 5) } \\
\text { with test strain }\end{array}$} \\
\hline & & $\begin{array}{l}\text { B. fragilis } \\
\text { ss. fragilis }\end{array}$ & $\begin{array}{l}\text { B. melaninogenicus } \\
\text { ss. asaccharolyticus }\end{array}$ \\
\hline BHI & $\begin{array}{l}\text { Tight } \\
\text { Loose }\end{array}$ & $\begin{array}{l}\mathbf{0} \\
\mathbf{2}\end{array}$ & $\begin{array}{l}\mathbf{0} \\
\mathbf{0}\end{array}$ \\
\hline ВHIДCMP & $\begin{array}{l}\text { Tight } \\
\text { Loose }\end{array}$ & $\begin{array}{l}3 \\
5\end{array}$ & $\begin{array}{l}3 \\
4\end{array}$ \\
\hline \multicolumn{2}{|c|}{ Inoculum size * } & $23 \cdot 5$ & c. $50 \dagger$ \\
\hline
\end{tabular}

- Mean no. of bacteria (cfu) inoculated per bottle †Estimated from total cell count.
Table 3 Comparison of recoveries obtained with 5 test strains in BHI/CMP and Thiol Broth

\begin{tabular}{|c|c|c|c|}
\hline \multirow[t]{2}{*}{ Test organism } & \multirow[t]{2}{*}{$\begin{array}{l}\text { Inoculum } \\
\text { size }\end{array}$} & \multicolumn{2}{|c|}{$\begin{array}{l}\text { Recovery (no. of bottles positive } \\
\text { out of 5) with the test me liun }\end{array}$} \\
\hline & & $B H I / C M P$ & Difco Thiol broth \\
\hline $\begin{array}{l}\text { B. fragilis ss. fragilis } \\
\text { B. melaninogenicus ss. }\end{array}$ & $3 \cdot 8$ & $4 \dagger$ & $5^{\mathrm{a}}(3)$ \\
\hline asaccharolyticus & 6.6 & $5 \ddagger$ & $2^{b}(5)$ \\
\hline $\begin{array}{l}\text { F. polymorphum } \\
\text { Anaerobic coccus }\end{array}$ & 6.6 & $5+$ & $0(5)$ \\
\hline $\begin{array}{l}\text { group I } \\
\text { Anaerobic coccus }\end{array}$ & $4 \cdot 3$ & $5+$ & $5+(2)$ \\
\hline group III & $29 \cdot 7$ & $5+(1)$ & $5+(2)$ \\
\hline
\end{tabular}

* Mean no. of bacteria (cfu) inoculated per bottle

84 at 2 days, but one bottle gave recovery only after 4 days' incubation 'Both bottles gave recovery only after 7 days' incubation

†These positives were recorded at 2 days

$\ddagger$ These positives were recorded at 4-5 days.

Numbers in parentheses show number of bottles contaminated between first subculture and end of 7 days' incubation.

Table 4 Recovery of eight test species in BHI/CMP medium

\begin{tabular}{lcl}
\hline Test organism & $\begin{array}{l}\text { Inoculum* } \\
\text { size }\end{array}$ & $\begin{array}{l}\text { Recovery (no. of bottles positive } \\
\text { out of 3) with the test strain }\end{array}$ \\
\hline Staph. aureus & 5.2 & 3 \\
E. coli & 8.4 & 3 \\
Ps. aeruginosa & 16.6 & 3 \\
Cl. welchii & 4.4 & 3 \\
Str. pneumoniae & 11.9 & 3 \\
Str. viridans & 14.5 & 3 \\
H. influenzae & $1.6 \dagger$ & 3 \\
N.meningitidis & 6.5 & $3^{\mathrm{a}}$ \\
\hline
\end{tabular}

* Mean no. of bacteria (ctu) inoculated per bottle

†This is an underestimate of bacterial cells because of clumping of bacterial cells.

aOne bottle gave recovery only after 7 days' incubation.

might be difficult to maintain as a routine. Contamination was avoided, but the Difco Thiol broth scored only one success out of five as compared with four successes out of five tests for the BHI/CMP broth.

BHI/CMP AS A GENERAL PURPOSE MEDIUM In further studies we tested the ability of BHI/CMP broth to support growth from a small inoculum of a wide range of likely pathogens. Table 4 gives the results. We achieved good recovery in all the tests within 48 hours, except in one bottle in the $N$. meningitidis set that required further incubation.

\section{Discussion}

The results obtained with Brain Heart Infusion broth (BHI medium) were unsatisfactory. Results with freshly prepared Brewer medium were apparently good, but cultures of test anaerobes in this medium tended to die within a few days. Cookedmeat broth supplemented with Brain Heart Infusion 
(BHI/CMP) gave good recovery and sustained viability with all test strains. Results with Difco Thiol broth were disappointing.

Forgan-Smith and Darrell (1974) ascribed the inactivation of organisms during growth in USP thioglycollate medium to the antibacterial action of acid produced and concluded that a routine blood culture procedure should also include a good cookedmeat medium. Dye (1975) found that toxic properties developed in sterile thioglycollate media during storage. Shanson (1974) did not favour USP thioglycollate broth; he obtained satisfactory results with a Southern Group Brewer's thioglycollate medium without liquoid; a cooked-meat digest broth with glucose also gave good results, but the S. G. Brewer's medium was slightly better. Shanson and Barnicoat (1975) regarded Difco Thiol broth as a suitable alternative to $S$. G. Brewer's medium. Szawatowski (1976) found that Difco Thiol medium was far superior to thioglycollate broth and cookedmeat broth with glucose for rapid isolation and quantitative growth of test strains of anaerobes that included $B$. fragilis (5 subspecies), B. melaninogenicus and various fusobacteria.

The above analysis of the recent literature indicates the confusion confronting the hospital bacteriologist. There are conflicting arguments for and against thioglycollate media, strong support for Difco Thiol broth (containing an unspecified Thiol compound), and conflicting claims for cooked-meat media. Our findings with a cooked-meat medium prepared from fresh bullock heart (see Cruickshank et al., 1975) supplemented with BHI medium and tested with a representative range of aerobes and anaerobes suggest that it is superior to thioglycollate media and to Difco Thiol medium. We found that the rubber bung of the Difco Thiol bottle is difficult to remove and to handle for routine subcultures without a significant risk of contamination; the use of a sterile syringe and needle for each subculture is a possible solution.

The supernate of sterile cooked-meat broth is usually slightly turbid. The common preference for a clear blood culture medium is understandable, but it should be borne in mind that turbidity may be a misleading indication of bacterial growth; we regularly confirmed that an early positive subculture can be obtained from a clear broth and that some turbid blood broths are sterile. Regular subcultures from all inoculated bottles to solid media are essential, and assessments of turbidity of the broth should not be allowed to influence the frequency of this check as a routine blood culture procedure.

In the preparation of blood culture media it is normal laboratory practice to autoclave bottles with their caps loose and to tighten the caps im- mediately after autoclaving while the bottles and their contents are still hot. Nevertheless, some laboratories autoclave blood culture bottles with the caps tight and our results indicate that this is unwise.

Some limitations of our model are clear. We used a laboratory-prepared inoculum of a stationary phase culture of stock organisms adapted to laboratory media, especially to cooked-meat broth, which we use regularly in this laboratory. We used defibrinated horse blood in place of human blood; outdated human transfusion blood was not used because it contains dextrose-citrate which would not normally be present in a blood culture. By inoculating a plate alternately with each test bottle we sought to demonstrate the range of the actual number of cells delivered and to estimate the probability of delivering no cells in the inoculum, which is a hazard of studies with intentionally small inocula. Results of intensive studies (to be reported elsewhere) with small inocula of strains of Bacteroides species from fluid cultures in stationary phase indicate that recoveries on solid media may vary from about $60-95 \%$ of the numbers predicted by careful microscopy. We must therefore assume that there is a possible underestimate of up to $40 \%$ in the cell counts for the minimal inocula of some of our exacting anaerobes. There may have been larger errors in the estimated inocula of the strain of $\boldsymbol{B}$. melaninogenicus ss. asaccharolyticus that could not be grown consistently from small inocula on solid media.

The relative costs (per 100 bottles) of the systems tested are as follows (September 1976): BHI medium $£ 11.36$, Brewer thioglycollate medium $£ 9 \cdot 11$, and BHI/CMP medium $£ 12.36$; these costs include $£ 7.61$ for 100 bottles (re-usable) plus 100 Viskaps and wires, but no allowance is made for technician-time or laboratory overheads. Difco Thiol broth costs approximately $£ 35+$ VAT + carriage for 100 bottles; the exact cost depends upon the number ordered.

In our experiments we attempted to simulate clinical microbiological problems in a carefully controlled laboratory model. Blazevic et al. (1975) undertook comparative studies in a clinical setting with 'real' specimens. They were limited by the demands of a continuing diagnostic commitment, and their conclusion that both an aerobic and anaerobic bottle are needed for blood culture was essentially based on their experience of the inadequacy of one system alone. We have attempted to assess our blood culture media in clinical practice; there are so many uncontrollable variables that a comparative trial is unlikely to give meaningful results and we favour an assessment based on a controlled laboratory model with a periodic review 
of performance in practice.

An ideal medium for a wide variety of potential pathogens might reasonably be rich in nutrients and would incorporate an effective non-toxic reducing system that would not exclude aerobes. These requirements were so well fulfilled by a combination of BHI and properly prepared cooked-meat particles in our studies that such a system perhaps merits wider recognition and clinical application.

We thank Professor B. P. Marmion for identifying the problem in a routine service area and for constructive discussions that led to this study, and we are grateful to Mrs S. Campbell for much technical help. This work was financed by the Medical Research Council (grant no. G 974/325B).

\section{References}

Blazevic, D. J., Stemper, J. E., and Matsen, J. M. (1975). Effect of aerobic and anaerobic atmospheres on isolation of organisms from blood cultures. Journal of Clinical Microbiology, 1, 154-156.

Brooks, K. and Sodeman, T. (1974). Rapid detection of bacteremia by a radiometric system: a clinical evaluation. American Journal of Clinical Pathology, 61, 859-866.

Chow, A. W. and Guze, L. B. (1974). Bacteroidaceae bacteremia: clinical experience with 112 patients. Medicine, 53, 93-126.

Collee, J. G., Watt, B., Fowler, E., and Brown, R. (1972). An evaluation of the Gaspak system in the culture of anaerobic bacteria. Journal of Applied Bacteriology, 35, 71-82.

Cruickshank, R., Duguid, J. P., Marmion, B. P., and Swain, R. H. A. (1975). Medical Microbiology, 12th edition, vol. 2, p. 122. Churchill Livingstone, Edinburgh, London and New York.

Duerden, B. I., Holbrook, W. P., Collee, J. G., and Watt, B. (1976). The characterization of clinically important Gram negative anaerobic bacilli by conventional bacteriological tests. Journal of Applied Bacteriology, 40, 163-188.

Dye, M. (1975). Anaerobic bacteria: a study of some problems in their isolation. Ph.D. Thesis, University of Aberdeen.

Forgan-Smith, W. R. and Darrell, J. H. (1974). A comparison of media used in vitro to isolate nonsporing Gram-negative anaerobes from blood. Journal of Clinical Pathology, 27, 280-283.

Gantz, N. M., Swain, J. L., Medeiros, A. A., and O'Brien, T. F. (1974). Vacuum blood-culture bottles inhibiting growth of Candida and fostering growth of Bacteroides. Lancet, 2, 1174-1176.

Shanson, D. C. (1974). An experimental assessment of different anaerobic blood culture methods. Journal of Clinical Pathology, 27, 273-279.

Shanson, D. C. and Barnicoat, M. (1975). An experimental comparison of Thiol broth with Brewer's thioglycollate for anaerobic blood cultures. Journal of Clinical Pathology, 28, 407-409.

Smith, A. G. and Little, R. R. (1974). Detection of bacteremia by an automated radiometric method and a tubed broth method. Annals of Clinical Laboratory Science, 4, 448-455.

Szawatowski, M. V. (1976). A comparison of three readily available types of anaerobic blood culture media. Medical Laboratory Sciences, 33, 5-12.

Thiemke, W. A. and Wicher, K. (1975). Laboratory experience with a radiometric method for detecting bacteremia. Journal of Clinical Microbiology, 1, 302-308.

Washington, J. A., II (1971). Comparison of two commercially available media for detection of bacteremia. Applied Microbiology, 22, 604-607.

Watt, B., Hoare, M. V. and Collee, J. G. (1973). Some variables affecting the recovery of anaerobic bacteria: a quantitative study. Journal of General Microbiology, 77, 447-454.

Wood, N. G. (1976). Comparative study of two systems for detecting bacteraemia and septicaemia. Journal of Clinical Pathology, 29, 530-533. 